\title{
Mediating Roles of PPARs in the Effects of Environmental Chemicals on Sex Steroids
}

\author{
Qiansheng Huang ${ }^{1,2}$ and Qionghua Chen ${ }^{3}$ \\ ${ }^{1}$ Key Lab of Urban Environment and Health, Institute of Urban Environment, Chinese Academy of Sciences, Xiamen 361021, China \\ ${ }^{2}$ Center for Excellence in Regional Atmospheric Environment, Institute of Urban Environment, Chinese Academy of Sciences, \\ Xiamen 361021, China \\ ${ }^{3}$ The First Affiliated Hospital of Xiamen University, Xiamen 361003, China
}

Correspondence should be addressed to Qiansheng Huang; qshuang@iue.ac.cn

Received 31 March 2017; Revised 23 May 2017; Accepted 21 June 2017; Published 27 July 2017

Academic Editor: Christopher Lau

Copyright (C) 2017 Qiansheng Huang and Qionghua Chen. This is an open access article distributed under the Creative Commons Attribution License, which permits unrestricted use, distribution, and reproduction in any medium, provided the original work is properly cited.

\begin{abstract}
Peroxisome proliferator-activated receptors (PPARs) are ligand-activated nuclear receptors that are widely involved in various physiological functions. They are widely expressed through the reproductive system. Their roles in the metabolism and function of sex steroids and thus the etiology of reproductive disorders receive great concern. Various kinds of exogenous chemicals, especially environmental pollutants, exert their adverse impact on the reproductive system through disturbing the PPAR signaling pathway. Chemicals could bind to PPARs and modulate the transcription of downstream genes containing PPRE (peroxisome proliferator response element). This will lead to altered expression of genes related to metabolism of sex steroids and thus the abnormal physiological function of sex steroids. In this review, various kinds of environmental ligands are summarized and discussed. Their interactions with three types of PPARs are classified by various data from transcript profiles, PPRE reporter in cell line, in silico docking, and gene silencing. The review will contribute to the understanding of the roles of PPARs in the reproductive toxicology of environmental chemicals.
\end{abstract}

\section{Introduction}

Peroxisome proliferator-activated receptors (PPARs) are ligand-activated nuclear receptors which are widely involved in various physiological and pathological processes [1]. The family contains three subtypes (PPAR $\alpha, \operatorname{PPAR} \beta / \delta$, and $\operatorname{PPAR} \gamma$ ) with various ligand specificity, tissue distribution, and biological function. PPARs are detectable in various compartments of the reproductive system, including hypothalamus, pituitary, testis, ovary, uterus, and adrenal and mammary gland. PPARs are widely involved in reproductive function, such as ovarian function, gestation, and communication between mother and fetus [2-4]. Sex steroids, also named as gonadal steroids, are defined as steroid hormones that interact with receptors of androgen, estrogen, and progesterone in vertebrates [5]. Sex steroids are produced by gonads (ovaries or testes) and adrenal glands. Further conversion could occur in other tissues such as livers and fats. PPARs are critical for the metabolism and physiological function of sex hormones $[2,6]$.

Large amounts of pollutants have been released into the environmental media as a consequence of rapid industrialization and urbanization. Exposure to pollutants has been reported to be a big risk for reproductive health [7]. The mechanism through which pollutants elicit adverse effects is still not fully understood. However, it is widely accepted that pollutants could adversely affect the reproductive function through disturbing the metabolism and function of sex steroids [8]. Pollutants could bind to PPARs and then modulate the PPAR signaling pathways involved in the reproductive function. Hydrophobic interactions are the primary driving force for the binding between pollutants and PPARs. Most of the amino acid residues are hydrophobic around the binding pocket which located inside the protein structure of PPARs [9]. The sequences of amino acids which form the pocket are conserved across species. Results from 
reporter cell lines also show that environmental ligands (BPA derivatives, phthalates, and PFAAs) share similar affinity for PPAR $\gamma$ of zebrafish and human [10].

In this review, the interactions between PPARs and sex steroids are presented. Various kinds of PPAR ligands, especially environmental chemicals, are summarized. The pathways through which exogenous chemicals exert their impact on the metabolism and function of sex steroids via PPARs are depicted.

\section{Interaction between PPARs and Sex Steroids}

Androgens and estrogens are the primary types of sex steroids. Exogenous testosterone significantly inhibited the expression of PPAR $\gamma$ in primary hepatocytes isolated from brown trout [11]. 17 $\beta$-Estradiol could regulate the expression of PPAR $\gamma$ in human peripheral blood eosinophils [12]. Additionally, precursors of sex steroids also interact with PPARs. For example, dehydroepiandrosterone (DHEA) induced elevated expression of both PPAR $\alpha$ and $\operatorname{PPAR} \beta / \delta$ in the muscle of mice [13]. Conversely, PPARs have an important impact on sex steroids. Single nucleotide polymorphism (SNP) of PPARs significantly affected the level of sex steroids and was linked to hormone related diseases. For example, the SNP of PPAR $\gamma$ at P12A (Pro12Ala, rs1801282) was linked to a gynecological disease: polycystic ovary syndrome (PCOS) as PCOS patients with CG genotype showed lower free testosterone and other hormones than that of GG genotype [14]. Peroxisome proliferators (PPs) are a group of chemicals which function through PPARs. PPs could impair the function of endocrine tissues by regulating the expression of phase I and phase II steroid metabolism enzymes [15], including P450 enzymes and $17 \beta$-hydroxysteroid dehydrogenase IV [16]. Apart from their impact on metabolism, PPs could also disturb the physiological function of sex steroids. They have been reported to mimic or interfere with the action of sex steroids and then induce reproductive disorders [17]. In addition, receptors of sex steroids were also reported to interplay with PPARs. For example, estrogen receptor alpha $(\mathrm{ER} \alpha)$ binds to the PPRE sequence of PPAR $\gamma$ and represses its transactivation in MCF-7 cells [18]. Bidirectional interplay occurs between PPAR $\gamma$ and ER [19].

Sources of PPs contain endogenous and exogenous chemicals. Endogenous essential fatty acids (FAs) and their derivative eicosanoids are able to activate the PPAR signaling pathway [20]. 17 $\beta$-Estradiol could suppress the expression of $\operatorname{PPAR} \alpha$ regulating genes [21]. In addition to these endogenous chemicals, chemicals from environmental media, drugs, and other external sources are also reported to disturb the PPAR signaling pathway and then affect metabolism and function of sex steroids.

\section{Environmental Chemicals as Exogenous Ligands}

A lot of environmental chemicals act as exogenous ligands to PPARs. These chemicals are widely detectable in the human body and have received widespread public health attention [52]. PPARs have been regarded as a bridge to link the environmental chemicals and their health impact [53]. Chemicals which could modulate the PPAR signaling pathway and affect the sex steroids are classified and listed as follows. They are also shown in Table 1.

3.1. Phthalates. Phthalates were widely reported as reproductive toxicants. Fetal exposure to environmentally relevant di(2-ethylhexyl) phthalate (DEHP) decreased serum levels of steroid hormones in adult male mice and antagonism of PPAR $\gamma$ diminished the toxic effect [22]. In our study, PPAR $\gamma$ was thought to transduce the toxicity of DEHP at $0.2-2 \mu \mathrm{M}$ in both primary cultured endometrial cells and endometrial adenocarcinoma cell line (ishikawa) [23]. We also obtained consistent results in a marine fish model where the expressions of PPAR $\gamma$ and aromatase were both enhanced after fish embryo exposure to DEHP at $0.1-1 \mathrm{mg} / \mathrm{L}$ [24]. In vivo, DEHP is metabolized to mono(2-ethylhexyl) phthalate (MEHP) which could activate both PPAR $\alpha$ and PPAR $\gamma$ and then suppress the transcription of aromatase and estradiol production in the ovary. These have been verified both in rat ovarian granulosa cell models [26] and in the ovary of rat models [25]. Direct exposure to MEHP at the dose of $50 \mu \mathrm{M}$ also inhibited the expression of aromatase by activating PPAR $\alpha$ or PPAR $\gamma$ in rat granulosa cells [27]. Due to the adverse health outcome of commonly used compounds, phthalate-alternative compounds have been emerging. Some of these chemicals also showed various affinities to PPARs and different influences on reproductive function according to docking studies [30, 54-56]. For example, diisononyl phthalate (DINP) showed DEHP-like affinity to PPAR $\alpha$. Di(2-ethylhexyl) terephthalate (DEHT) has the paraisomer structure of DEHP and shows a very weak affinity to PPAR $\alpha$.

3.2. Perfluoroalkyl Acids. Perfluoroalkyl acids (PFAAs), characteristic of fully fluorinated carbon chains, are widely used in consumer goods and industrial products. Concerns have arisen regarding human exposure and adverse outcome, especially due to extremely long biologic retention time [57]. Treatments with perfluorononanoic acid (PFNA), perfluorooctanoic acid (PFOA), perfluorodecanoic acid (PFDA), perfluoroundecanoic acid (PFUnDA), and perfluorooctane sulfonate (PFOS) all dose-dependently activated PPAR $\alpha$ using a PPRE reporter system [31, 33]. PFOS and PFOA are top two members in toxicological studies. Our study showed that the effects of PFOS $(1-16 \mathrm{mg} / \mathrm{L})$ were different on the expression of these three types of PPARs in the larvae of O. melastigma [37]. PFOA (5 mg/kg) exposure affected the expression of PPARs in a tissue dependent manner in fetal and postnatal CD-1 mice [34]. Both PFOS and PFOA can induce PPARs-mediated transcriptional activity determined by PPRE reporter assay [31, 33, 35, 36, 38, 39]. This led to alterations in immune response and other physiological processes [58]. However, the mediating roles of PPARs are not consistently recognized. Several studies confirm that PFOA can exert its toxicity independently of PPAR $\alpha[59,60]$. It is worth mentioning that four weeks' PFOA treatment $(5 \mathrm{mg} / \mathrm{kg}$ ) increased the expression of enzymes catalyzing the biosynthesis of steroid hormone and enhanced serum levels of progesterone in PPAR $\alpha$ knockout female mice [61]. Apart 


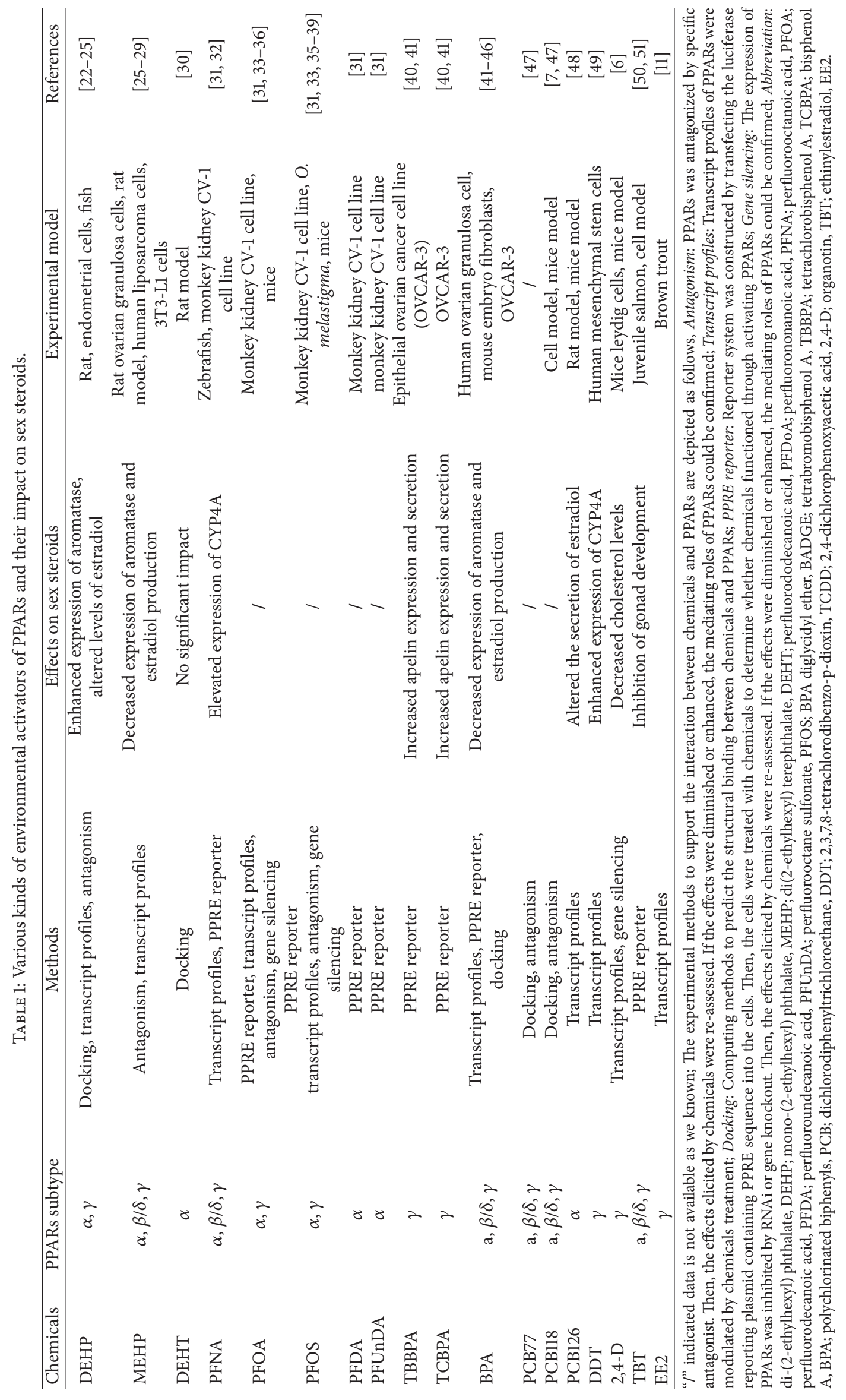


from the toxicological studies, a lot of epidemiological studies also revealed the effects of PFOA on reproduction. Positive or negative association was reported by publications from C8 science panel [62-64]. Different members of PFAAs show various impacts on PPAR signaling due to their various chain lengths and functional groups $[65,66]$. Thus, toxicities of other family members are being studied. For example, perfluorododecanoic acid (PFDoA) administration $(3 \mathrm{mg} / \mathrm{kg}$ ) led to reduced serum levels of $17 \beta$-estradiol in prepubertal female rats; however, the roles of PPARs have not been verified yet [67].

3.3. Bisphenol A (BPA) and Its Derivatives. BPA is widely used in plastic bottles, paper, and other daily commodities. Due to structural similarity with $17 \beta$-estradiol, the estrogenic activity of BPA via ER activation was widely studied. In addition to ERs, BPA also show an affinity to human PPAR $\gamma$ as confirmed by data from docking and PPRE reporter studies $[9,42,43]$. The affinity was ranked as $\operatorname{ERR} \gamma>\operatorname{ER} \alpha>\operatorname{PPAR} \gamma$. BPA exposure $(0-100 \mu \mathrm{M})$ led to reduced expression of aromatase and decreased level of E2 secretion in human ovarian granulosa cells, which also happened after overexpression of the PPAR $\gamma$ [44]. By contrast, the same level range of BPA showed no significant effect on the expression of both PPAR $\gamma$ and aromatase in human endometrial stromal fibroblast cells [68]. To be noted, low dose effects were observed in the toxicology of BPA. A low dose was considered to be a dose below the range typically used in toxicological studies of chemicals [69]. Biphasic U- or inverted U-shaped doseresponse curves have been observed when evaluating the effects of BPA on reproduction and other health outcomes. Competitive binding to PPARs and other receptors between BPA and sex hormone might contribute to this low dose effect [70]. Derivatives of BPA could also interfere with PPARs. Brominated or chlorinated derivatives of BPA display their adverse impact through PPARs. Both tetrabromobisphenol A (TBBPA) and tetrachlorobisphenol A (TCBPA) show binding affinity to PPAR $\gamma$ as indicated by reporter cell lines $[40,71]$. Of further note, TBBPA $(0.01-10 \mu \mathrm{M})$ can also induce the expression of aromatase and thus enhance estrogen synthesis independently of PPAR $\gamma$ in human choriocarcinoma JEG-3 cells $[72,73]$.

3.4. Dioxin-Like Chemicals. Dioxin and its structure-like chemicals are widely accepted as the ligands to aryl hydrocarbon receptor (AHR). They also interplay with PPARs as confirmed by in silico docking experiments [47]. An in vivo study using male rat model revealed that polychlorinated biphenyls 126 (PCB126) exposure at the dose of $5 \mu \mathrm{mol} / \mathrm{kg}$ inhibited the mRNA expression of PPAR $\alpha$ and its downstream genes acyl-CoA oxidase (Acox1) and hydroxy3-methylglutaryl-CoA synthase 2 (Hmgcs2) in liver [48]. In our study using both cells and mice models, PCB126 exposure at human relevant levels induces the expression of HSD17B7 and enhances the secretion of estradiol in endometrium [7]. Molecular evidence confirmed the existence of two PPRE sites at the promoter of cytochrome P4501A1 (CYP1A1). Thus, direct activation of CYP1A1 by PPAR $\alpha$ without AHR might be a new pathway to link PCBs and PPARs $[74,75]$.
However, strong evidence is still needed to confirm the link.

3.5. Pesticides. A lot of pesticides show disrupting effects on metabolism and function of sex steroids, such as deltamethrin [76], linuron [77], and methomyl [78]. The mediating function of PPARs is being studied in the toxicity of pesticides. For example, a large in vitro reporter gene assay screening study with 200 pesticides showed that PPARs did not have a major role in the toxicity of pesticides. Various kinds of pesticides were examined including 29 organochlorines, 11 diphenyl ethers, 56 organophosphorus pesticides, 12 pyrethroids, 22 carbamates, 11 acid amides, 7 triazines, 8 ureas, and 44 others. Results showed that only three (diclofop-methyl, pyrethrins, and imazalil) could activate PPAR $\alpha$ and none of them could activate PPAR $\gamma$. The agonist roles of these three pesticides were further confirmed in mice [79]. In a study that has raised wide ecotoxicological concern, the mRNA level of PPAR $\gamma$ was induced by DDT at the doses of $100 \mathrm{pM}-10 \mu \mathrm{M}$ in human mesenchymal stem cells [49]. To be noted, direct evidence is still expected on the effects of pesticides on sex steroids through PPAR signaling.

3.6. Other Pollutants. Organotin compounds are ubiquitously present in environment media. The compounds have been reported to alter endocrine functions in juvenile salmon and human choriocarcinoma cell lines $[50,80]$. Tributyltin (TBT) could activate all three types of RXR (retinoid X receptor): $\operatorname{PPAR} \alpha, \operatorname{PPAR} \beta / \delta$, and $\operatorname{PPAR} \gamma$ heterodimers by PPRE luciferase experiment [51]. 2,4-Dichlorophenoxyacetic acid (2,4-D) is a possible endocrine disruptor. Treatment with 2,4-D decreased the level of testosterone in mice serum and testis through inhibiting the expression of 3-hydroxy-3methylglutaryl coenzyme A synthase 1 and reductase, which led to decreased cholesterol levels. PPAR $\alpha$ exerted a critical role as its silencing diminished these toxic effects [6].

3.7. Pollutant Mixtures. In addition to individual pollutants, chemical mixtures also display reproductive toxicity through PPARs. Combined exposure to 2,3,7,8-tetrachlorodibenzo-pdioxin (TCDD) and DEHP led to decreased estradiol synthesis in human granulosa cell line-KGN. Direct activation of AHR and transactivation of PPARs are indispensable parts in this molecular response pathway [81]. Chemical mixtures extracted from natural water could also disturb the function of steroid hormones where PPARs act as key regulators $[82,83]$. In our study, cotreatment with DEHP and PCBs promoted the expression of PPAR $\gamma$ but not the other PPAR types in mice liver [84].

\section{Conclusion and Perspectives}

PPARs, especially the subtype of $\alpha$ and $\gamma$, have important roles in mediating the toxicological outcomes caused by environmental ligands. Various kinds of environmental pollutants show impacts on the metabolism and function of sex steroids through disturbing the PPARs signaling pathways. The interactions between PPARs and environmental chemicals have been revealed through various approaches 
including molecular docking, PPRE reporter, transcript profiles, and gene silencing which are performed in silico, in vitro, and in vivo. Future studies that should be carried out include (1) structural biological studies on crystal structures of pollutants bound to PPARs and (2) further evaluation of the crosstalk between PPARs and other classical nuclear receptors, such as ER and AHR. These studies will help reveal the roles of PPARs in the toxicology of environmental pollutants on sex steroids.

\section{Conflicts of Interest}

The authors declare that there are no conflicts of interest regarding the publication of this article.

\section{Acknowledgments}

This work was supported by the National Natural Science Foundation of China (21477123 and 81571418).

\section{References}

[1] B. Gross, M. Pawlak, P. Lefebvre, and B. Staels, "PPARs in obesity-induced T2DM, dyslipidaemia and NAFLD," Nature Reviews Endocrinology, vol. 13, no. 1, pp. 36-49, 2017.

[2] M. Vitti, G. Di Emidio, M. Di Carlo et al., "Peroxisome proliferator-activated receptors in female reproduction and fertility," PPAR Research, vol. 2016, Article ID 4612306, 12 pages, 2016.

[3] J. Yang, L. Chen, X. Zhang et al., "PPARs and female reproduction: evidence from genetically manipulated mice," $P P A R$ Research, vol. 2008, Article ID 723243, 8 pages, 2008.

[4] P. Froment, F. Gizard, D. Defever, B. Staels, J. Dupont, and P. Monget, "Peroxisome proliferator-activated receptors in reproductive tissues: from gametogenesis to parturition," Journal of Endocrinology, vol. 189, no. 2, pp. 199-209, 2006.

[5] G. Guerriero, "Vertebrate sex steroid receptors: Evolution, ligands, and neurodistribution," Annals of the New York Academy of Sciences, vol. 1163, pp. 154-168, 2009.

[6] Y. Harada, N. Tanaka, M. Ichikawa et al., "PPAR $\alpha$-dependent cholesterol/testosterone disruption in Leydig cells mediates 2,4-dichlorophenoxyacetic acid-induced testicular toxicity in mice," Archives of Toxicology, vol. 90, no. 12, pp. 3061-3071, 2016.

[7] Q. Huang, Y. Chen, Q. Chen et al., "Dioxin-like rather than nondioxin-like PCBs promote the development of endometriosis through stimulation of endocrine-inflammation interactions," Archives of Toxicology, vol. 91, no. 4, pp. 1915-1924, 2017.

[8] Z. R. Craig, W. Wang, and J. A. Flaws, "Endocrine-disrupting chemicals in ovarian function: Effects on steroidogenesis, metabolism and nuclear receptor signaling," Reproduction, vol. 142, no. 5, pp. 633-646, 2011.

[9] L. Li, Q. Wang, Y. Zhang, Y. Niu, X. Yao, and H. Liu, "The molecular mechanism of bisphenol A (BPA) as an endocrine disruptor by interacting with nuclear receptors: Insights from molecular dynamics (MD) simulations," PLoS ONE, vol. 10, no. 3, Article ID e0120330, 2015.

[10] M. Grimaldi, A. Boulahtouf, V. Delfosse, E. Thouennon, W. Bourguet, and P. Balaguer, "Reporter Cell Lines to Evaluate The Selectivity of Chemicals for Human and Zebrafish Estrogen and Peroxysome Proliferator Activated $\gamma$ Receptors," Frontiers in Neuroscience, vol. 9, Article ID 00212, 212 pages, 2015.
[11] C. Lopes, T. V. Madureira, N. Ferreira, I. Pinheiro, L. F. C. Castro, and E. Rocha, "Peroxisome proliferator-activated receptor gamma $(\operatorname{PPAR} \gamma)$ in brown trout: Interference of estrogenic and androgenic inputs in primary hepatocytes," Environmental Toxicology and Pharmacology, vol. 46, pp. 328-336, 2016.

[12] S. Ueki, M. Oguma, A. Usami et al., "Regulation of peroxisome proliferator-activated receptor- $\gamma$ expression in human eosinophils by estradiol," International Archives of Allergy and Immunology, vol. 149, Supplement 1, pp. 51-56, 2009.

[13] N. Horii, K. Sato, N. Mesaki, and M. Iemitsu, "DHEA Administration Activates Transcription of Muscular Lipid Metabolic Enzymes via PPAR $\alpha$ and PPAR $\delta$ in Obese Rats," Hormone and Metabolic Research, vol. 48, no. 3, pp. 207-212, 2016.

[14] M. Yilmaz et al., "Pro12Ala polymorphism of the peroxisome proliferator-activated receptor-gamma gene in women with polycystic ovary syndrome," Gynecological Endocrinology, vol. 22, no. 6, pp. 336-342, 2006.

[15] L.-Q. Fan, L. You, H. Brown-Borg, S. Brown, R. J. Edwards, and J. C. Corton, "Regulation of phase I and phase II steroid metabolism enzymes by PPAR $\alpha$ activators," Toxicology, vol. 204, no. 2-3, pp. 109-121, 2004.

[16] L.-Q. Fan, R. C. Cattley, and J. C. Corton, "Tissue-specific induction of $17 \beta$-hydroxysteroid dehydrogenase type IV by peroxisome proliferator chemicals is dependent on the peroxisome proliferator-activated receptor $\alpha$," Journal of Endocrinology, vol. 158, no. 2, pp. 237-246, 1998.

[17] S. De Coster and N. van Larebeke, "Endocrine-disrupting chemicals: associated disorders and mechanisms of action," Journal of Environmental and Public Health, vol. 2012, Article ID 713696, 52 pages, 2012.

[18] D. Bonofiglio, S. Gabriele, S. Aquila et al., "Estrogen receptor $\alpha$ binds to peroxisome proliferator-activated receptor response element and negatively interferes with peroxisome proliferatoractivated receptor $\gamma$ signaling in breast cancer cells," Clinical Cancer Research, vol. 11, no. 17, pp. 6139-6147, 2005.

[19] X. Wang and M. W. Kilgore, "Signal cross-talk between estrogen receptor alpha and beta and the peroxisome proliferatoractivated receptor gammal in MDA-MB-231 and MCF-7 breast cancer cells," Molecular and Cellular Endocrinology, vol. 194, no. 1-2, pp. 123-133, 2002.

[20] F. Echeverría, M. Ortiz, R. Valenzuela, and L. A. Videla, "Long-chain polyunsaturated fatty acids regulation of PPARs, signaling: Relationship to tissue development and aging," Prostaglandins Leukotrienes and Essential Fatty Acids, vol. 114, pp. 28-34, 2016.

[21] M. Yoon, "PPAR $\alpha$ in obesity: sex difference and estrogen involvement," PPAR Research, vol. 2010, Article ID 584296, 16 pages, 2010.

[22] S. Lee, D. B. Martinez-Arguelles, E. Campioli, and V. Papadopoulos, "Fetal exposure to low levels of the plasticizer DEHP predisposes the adult male adrenal gland to endocrine disruption," Endocrinology, vol. 158, no. 2, pp. 304-318, 2017.

[23] Q. S. Huang et al., "The inflammation response to DEHP through PPAR gamma in endometrial cells," International Journal of Environmental Research and Public Health, vol. 13, no. 3, p. 13, 2016.

[24] T. Ye, M. Kang, Q. Huang et al., "Accumulation of Di(2ethylhexyl) Phthalate Causes Endocrine-Disruptive Effects in Marine Medaka (Oryzias melastigma) Embryos," Environmental Toxicology, vol. 31, no. 1, pp. 116-127, 2016.

[25] C. Xu, J.-A. Chen, Z. Qiu et al., "Ovotoxicity and PPARmediated aromatase downregulation in female Sprague-Dawley 
rats following combined oral exposure to benzo[a]pyrene and di-(2-ethylhexyl) phthalate," Toxicology Letters, vol. 199, no. 3, pp. 323-332, 2010.

[26] T. Lovekamp-Swan, A. M. Jetten, and B. J. Davis, "Dual activation of PPAR $\alpha$ and PPAR $\gamma$ by mono-(2-ethylhexyl) phthalate in rat ovarian granulosa cells," Molecular and Cellular Endocrinology, vol. 201, no. 1-2, pp. 133-141, 2003.

[27] T. Lovekamp-Swan and B. J. Davis, "Mechanisms of phthalate ester toxicity in the female reproductive system," Environmental Health Perspectives, vol. 111, no. 2, pp. 139-145, 2003.

[28] E. Campioli, A. Batarseh, J. Li, and V. Papadopoulos, "The endocrine disruptor mono-(2-ethylhexyl) phthalate affects the differentiation of human liposarcoma cells (SW 872)," PLoS ONE, vol. 6, no. 12, Article ID e28750, 2011.

[29] J. N. Feige, L. Gelman, D. Rossi et al., "The endocrine disruptor monoethyl-hexyl-phthalate is a selective peroxisome proliferator-activated receptor $\gamma$ modulator that promotes adipogenesis," Journal of Biological Chemistry, vol. 282, no. 26, pp. 19152-19166, 2007.

[30] M. A. Babich, "Review of Exposure And Toxicity Data for Phthalate Substitutes," Tech. Rep., 2010, http://www.cpsc.gov/ PageFiles/126546/phthalsub.pdf.

[31] H. Ishibashi, H. Iwata, E.-Y. Kim et al., "Contamination and effects of perfluorochemicals in baikal seal (Pusa sibirica). 2. Molecular characterization, expression level, and transcriptional activation of peroxisome proliferator-activated receptor $\alpha$, Environmental Science and Technology, vol. 42, no. 7, pp. 2302-2308, 2008.

[32] W. Zhang, Y. Zhang, H. Zhang, J. Wang, R. Cui, and J. Dai, "Sex differences in transcriptional expression of FABPs in zebrafish liver after chronic perfluorononanoic acid exposure," Environmental Science and Technology, vol. 46, no. 9, pp. 51755182, 2012.

[33] H. Ishibashi, E.-Y. Kim, and H. Iwata, “Transactivation potencies of the Baikal seal (Pusa sibirica) peroxisome proliferatoractivated receptor $\alpha$ by perfluoroalkyl carboxylates and sulfonates: Estimation of PFOA induction equivalency factors," Environmental Science and Technology, vol. 45, no. 7, pp. 31233130, 2011.

[34] B. D. Abbott, C. R. Wood, A. M. Watkins, K. Tatum-Gibbs, K. P. Das, and C. Lau, "Effects of perfluorooctanoic acid (PFOA) on expression of peroxisome proliferator-activated receptors (PPAR) and nuclear receptor-regulated genes in fetal and postnatal CD-1 mouse tissues," Reproductive Toxicology, vol. 33, no. 4, pp. 491-505, 2012.

[35] W. Xia, Y.-J. Wan, X. Wang et al., "Sensitive bioassay for detection of PPAR $\alpha$ potentially hazardous ligands with gold nanoparticle probe," Journal of Hazardous Materials, vol. 192, no. 3, pp. 1148-1154, 2011.

[36] J. P. Vanden Heuvel, J. T. Thompson, S. R. Frame, and P. J. Gillies, "Differential activation of nuclear receptors by perfluorinated fatty acid analogs and natural fatty acids: A comparison of human, mouse, and rat peroxisome proliferator-activated receptor- $\alpha,-\beta$, and $-\gamma$, liver $\mathrm{X}$ receptor- $\beta$, and retinoid $\mathrm{X}$ receptor- $\alpha$," Toxicological Sciences, vol. 92, no. 2, pp. 476-489, 2006.

[37] C. Fang, X. Wu, Q. Huang et al., "PFOS elicits transcriptional responses of the ER, AHR and PPAR pathways in Oryzias melastigma in a stage-specific manner," Aquatic Toxicology, vol. 106-107, pp. 9-19, 2012.

[38] M. L. Takacs and B. D. Abbott, "Activation of mouse and human peroxisome proliferator-activated receptors $(\alpha, \beta / \delta$, $\gamma)$ by perfluorooctanoic acid and perfluorooctane sulfonate," Toxicological Sciences, vol. 95, no. 1, pp. 108-117, 2007.

[39] J. M. Shipley, C. H. Hurst, S. S. Tanaka et al., "transactivation of PPAR $\alpha$ and induction of PPAR $\alpha$ target genes by perfluorooctane-based chemicals," Toxicological Sciences, vol. 80, no. 1, pp. 151-160, 2004.

[40] A. Riu, M. Grimaldi, A. le Maire et al., "Peroxisome proliferatoractivated receptor $\gamma$ is a target for halogenated analogs of bisphenol A," Environmental Health Perspectives, vol. 119, no. 9, pp. 1227-1232, 2011.

[41] M. Hoffmann, E. Fiedor, and A. Ptak, "Bisphenol A and its derivatives tetrabromobisphenol $\mathrm{A}$ and tetrachlorobisphenol A induce apelin expression and secretion in ovarian cancer cells through a peroxisome proliferator-activated receptor gammadependent mechanism," Toxicology Letters, vol. 269, pp. 15-22, 2017.

[42] G. Biasiotto, I. Zanella, A. Masserdotti et al., "Municipal wastewater affects adipose deposition in male mice and increases 3T3-L1 cell differentiation," Toxicology and Applied Pharmacology, vol. 297, pp. 32-40, 2016.

[43] D. Montes-Grajales and J. Olivero-Verbel, "Computer-aided identification of novel protein targets of bisphenol A," Toxicology Letters, vol. 222, no. 3, pp. 312-320, 2013.

[44] J. Kwintkiewicz, Y. Nishi, T. Yanase, and L. C. Giudice, "Peroxisome proliferator-activated receptor- $\gamma$ mediates bisphenol A inhibition of FSH-stimulated IGF-1, aromatase, and estradiol in human granulosa cells," Environmental Health Perspectives, vol. 118 , no. 3, pp. 400-406, 2010.

[45] C. H. Hurst and D. J. Waxman, "Activation of PPAR $\alpha$ and PPAR $\gamma$ by environmental phthalate monoesters," Toxicological Sciences, vol. 74, no. 2, pp. 297-308, 2003.

[46] E. Grasselli, K. Cortese, A. Voci et al., "Direct effects of Bisphenol A on lipid homeostasis in rat hepatoma cells," Chemosphere, vol. 91, no. 8, pp. 1123-1129, 2013.

[47] I. A. Sheikh, A. A. Khweek, and M. A. Beg, "Peroxisome proliferator-activated receptors as potential targets for carcinogenic activity of polychlorinated biphenyls: A computational perspective," Anticancer Research, vol. 36, no. 11, pp. 6117-6124, 2016.

[48] G. S. Gadupudi, W. D. Klaren, A. K. Olivier, A. J. Klingelhutz, and L. W. Robertson, "PCB126-induced disruption in gluconeogenesis and fatty acid oxidation precedes fatty liver in male rats," Toxicological Sciences, vol. 149, no. 1, pp. 98-110, 2016.

[49] A. L. Strong, Z. Shi, M. J. Strong et al., "Effects of the endocrinedisrupting chemical DDT on self-renewal and differentiation of human Mesenchymal stem cells," Environmental Health Perspectives, vol. 123, no. 1, pp. 42-48, 2015.

[50] N. Pavlikova, T. M. Kortner, and A. Arukwe, "Modulation of acute steroidogenesis, peroxisome proliferator-activated receptors and CYP3A/PXR in salmon interrenal tissues by tributyltin and the second messenger activator, forskolin," ChemicoBiological Interactions, vol. 185, no. 2, pp. 119-127, 2010.

[51] A. le Maire, M. Grimaldi, D. Roecklin et al., "Activation of RXRPPAR heterodimers by organotin environmental endocrine disruptors," EMBO Reports, vol. 10, no. 4, pp. 367-373, 2009.

[52] CDC, "Fourth national report on human exposure to environmental chemicals," 2009, http://www.cdc.gov/exposurereport/.

[53] J. Mathieu-Denoncourt, S. J. Wallace, S. R. de Solla, and V. S. Langlois, "Plasticizer endocrine disruption: Highlighting developmental and reproductive effects in mammals and non-mammalian aquatic species," General and Comparative Endocrinology, vol. 216, pp. 74-88, 2015. 
[54] N. Kambia, A. Farce, K. Belarbi et al., "Docking study: PPARs interaction with the selected alternative plasticizers to $\mathrm{di}(2-$ ethylhexyl) phthalate," Journal of Enzyme Inhibition and Medicinal Chemistry, vol. 31, no. 3, pp. 448-455, 2016.

[55] M. K. Sarath Josh, S. Pradeep, K. S. Vijayalekshmi Amma et al., "Phthalates efficiently bind to human peroxisome proliferator activated receptor and retinoid X receptor $\alpha, \beta, \gamma$ subtypes: an in silico approach," Journal of Applied Toxicology, vol. 34, no. 7, pp. 754-765, 2014.

[56] T. Kaya, S. C. Mohr, D. J. Waxman, and S. Vajda, "Computational screening of phthalate monoesters for binding to PPAR $\gamma$," Chemical Research in Toxicology, vol. 19, no. 8, pp. 999-1009, 2006.

[57] Z. Wang, I. T. Cousins, M. Scheringer, and K. Hungerbuehler, "Hazard assessment of fluorinated alternatives to long-chain perfluoroalkyl acids (PFAAs) and their precursors: Status quo, ongoing challenges and possible solutions," Environment International, vol. 75, pp. 172-179, 2015.

[58] J. C. DeWitt, A. Shnyra, M. Z. Badr et al., "Immunotoxicity of perfluorooctanoic acid and perfluorooctane sulfonate and the role of peroxisome proliferator-activated receptor alpha," Critical Reviews in Toxicology, vol. 39, no. 1, pp. 76-94, 2009.

[59] A. J. Filgo, E. M. Quist, M. J. Hoenerhoff, A. E. Brix, G. E. Kissling, and S. E. Fenton, "Perfluorooctanoic acid (PFOA)induced liver lesions in two strains of mice following developmental exposures: PPAR $\alpha$ is not required," Toxicologic Pathology, vol. 43, no. 4, pp. 558-568, 2015.

[60] A. Mattsson, A. Kärrman, R. Pinto, and B. Brunström, "Metabolic profiling of chicken embryos exposed to perfluorooctanoic acid (PFOA) and agonists to peroxisome proliferatoractivated receptors," PLoS ONE, vol. 10, no. 12, 2015.

[61] Y. Zhao, Y. S. Tan, S. Z. Haslam, and C. Yang, "Perfluorooctanoic acid effects on steroid hormone and growth factor levels mediate stimulation of peripubertal mammary gland development in C57Bl/6 mice," Toxicological Sciences, vol. 115, no. 1, pp. 214-224, 2010.

[62] D. A. Savitz, C. R. Stein, S. M. Bartell et al., "Perfluorooctanoic acid exposure and pregnancy outcome in a highly exposed community," Epidemiology, vol. 23, no. 3, pp. 386-392, 2012.

[63] D. A. Savitz, C. R. Stein, B. Elston et al., "Relationship of perfluorooctanoic acid exposure to pregnancy outcome based on birth records in the mid-Ohio valley," Environmental Health Perspectives, vol. 120, no. 8, pp. 1201-1207, 2012.

[64] L. A. Darrow, C. R. Stein, and K. Steenland, "Serum perfluorooctanoic acid and perfluorooctane sulfonate concentrations in relation to birth outcomes in the Mid-Ohio Valley, 20052010," Environmental Health Perspectives, vol. 121, no. 10, pp. 1207-1213, 2013.

[65] J. A. Bjork and K. B. Wallace, "Structure-activity relationships and human relevance for perfluoroalkyl acid-induced transcriptional activation of peroxisome proliferation in liver cell cultures," Toxicological Sciences, vol. 111, no. 1, pp. 89-99, 2009.

[66] T. Buhrke, A. Kibellus, and A. Lampen, "In vitro toxicological characterization of perfluorinated carboxylic acids with different carbon chain lengths," Toxicology Letters, vol. 218, no. 2, pp. 97-104, 2013.

[67] Z. Shi, H. Zhang, L. Ding, Y. Feng, M. Xu, and J. Dai, “The effect of perfluorododecanonic acid on endocrine status, sex hormones and expression of steroidogenic genes in pubertal female rats," Reproductive Toxicology, vol. 27, no. 3-4, pp. 352359, 2009.
[68] L. Aghajanova and L. C. Giudice, "Effect of bisphenol A on human endometrial stromal fibroblasts in vitro," Reproductive BioMedicine Online, vol. 22, no. 3, pp. 249-256, 2011.

[69] W. V. Welshons, K. A. Thayer, B. M. Judy, J. A. Taylor, E. M. Curran, and F. S. vom Saal, "Large effects from small exposures. I. Mechanisms for endocrine-disrupting chemicals with estrogenic activity," Environmental Health Perspectives, vol. 111, no. 8, pp. 994-1006, 2003.

[70] F. Acconcia, V. Pallottini, and M. Marino, "Molecular mechanisms of action of BPA," Dose-Response, vol. 13, no. 4, 2015.

[71] A. Riu, A. le Maire, M. Grimaldi et al., "Characterization of Novel Ligands of $\operatorname{ER} \alpha, \operatorname{Er} \beta$, and PPAR $\gamma$ : The Case of Halogenated Bisphenol A and Their Conjugated Metabolites," Toxicological Sciences, vol. 122, no. 2, pp. 372-382, 2011.

[72] E. Honkisz and A. K. Wójtowicz, "Modulation of estradiol synthesis and aromatase activity in human choriocarcinoma JEG-3 cells exposed to tetrabromobisphenol A," Toxicology in Vitro, vol. 29, no. 1, pp. 44-50, 2015.

[73] E. Honkisz and A. K. Wójtowicz, "The role of PPAR $\gamma$ in TBBPAmediated endocrine disrupting effects in human choriocarcinoma JEG-3 cells," Molecular and Cellular Biochemistry, vol. 409, no. 1-2, pp. 81-91, 2015.

[74] E. Sérée, P.-H. Villard, J.-M. Pascussi et al., "Evidence for a new human CYP1A1 regulation pathway involving PPAR- $\alpha$ and 2 PPRE sites," Gastroenterology, vol. 127, no. 5, pp. 1436-1445, 2004.

[75] F. Fallone, P.-H. Villard, L. Decome et al., "PPAR $\alpha$ activation potentiates AhR-induced CYP1A1 expression," Toxicology, vol. 216, no. 2-3, pp. 122-128, 2005.

[76] A. Ben Slima, Y. Chtourou, M. Barkallah, H. Fetoui, T. Boudawara, and R. Gdoura, "Endocrine disrupting potential and reproductive dysfunction in male mice exposed to deltamethrin," Human \& Experimental Toxicology, vol. 36, no. 3, pp. 218-226, 2017.

[77] H. Ding, W. Zheng, H. Han et al., "Reproductive toxicity of linuron following gestational exposure in rats and underlying mechanisms," Toxicology Letters, vol. 266, pp. 49-55, 2017.

[78] S. L. Meng, L. P. Qiu, G. D. Hu et al., "Responses and recovery pattern of sex steroid hormones in testis of Nile tilapia (Oreochromis niloticus) exposed to sublethal concentration of methomyl," Ecotoxicology, vol. 25, no. 10, pp. 1805-1811, 2016.

[79] S. Takeuchi, T. Matsuda, S. Kobayashi, T. Takahashi, and H. Kojima, "In vitro screening of 200 pesticides for agonistic activity via mouse peroxisome proliferator-activated receptor (PPAR) $\alpha$ and PPAR $\gamma$ and quantitative analysis of in vivo induction pathway," Toxicology and Applied Pharmacology, vol. 217, no. 3, pp. 235-244, 2006.

[80] T. Nakanishi, J.-I. Nishikawa, Y. Hiromori et al., "Trialkyltin compounds bind retinoid $\mathrm{X}$ receptor to alter human placental endocrine functions," Molecular Endocrinology, vol. 19, no. 10, pp. 2502-2516, 2005.

[81] J. Ernst, J.-C. Jann, R. Biemann, H. M. Koch, and B. Fischer, "Effects of the environmental contaminants DEHP and TCDD on estradiol synthesis and aryl hydrocarbon receptor and peroxisome proliferator-activated receptor signalling in the human granulosa cell line KGN," Molecular Human Reproduction, vol. 20, no. 9, pp. 919-928, 2014.

[82] J. L. Lyche, R. Nourizadeh-Lillabadi, C. Karlsson et al., "Natural mixtures of POPs affected body weight gain and induced transcription of genes involved in weight regulation and insulin signaling," Aquatic Toxicology, vol. 102, no. 3-4, pp. 197-204, 2011. 
[83] J. L. Lyche, R. Nourizadeh-Lillabadi, C. Almaas et al., "Natural mixtures of persistent organic pollutants (POP) increase weight gain, advance puberty, and induce changes in gene expression associated with steroid hormones and obesity in female zebrafish," Journal of Toxicology and Environmental Health, Part A: Current Issues, vol. 73, no. 15, pp. 1032-1057, 2010.

[84] Y. Lin, L. Min, Q. Huang et al., "The combined effects of DEHP and PCBs on phospholipase in the livers of mice," Environmental Toxicology, vol. 30, no. 2, pp. 197-204, 2015. 


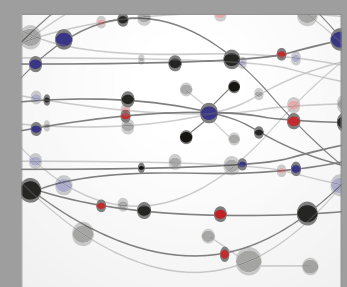

The Scientific World Journal
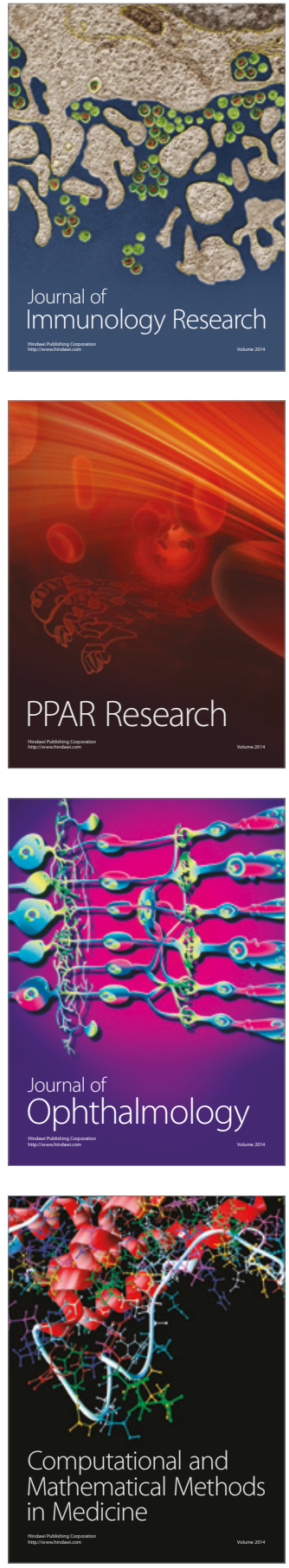

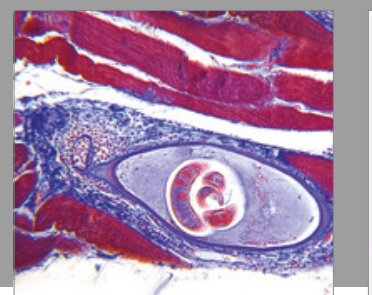

Gastroenterology Research and Practice
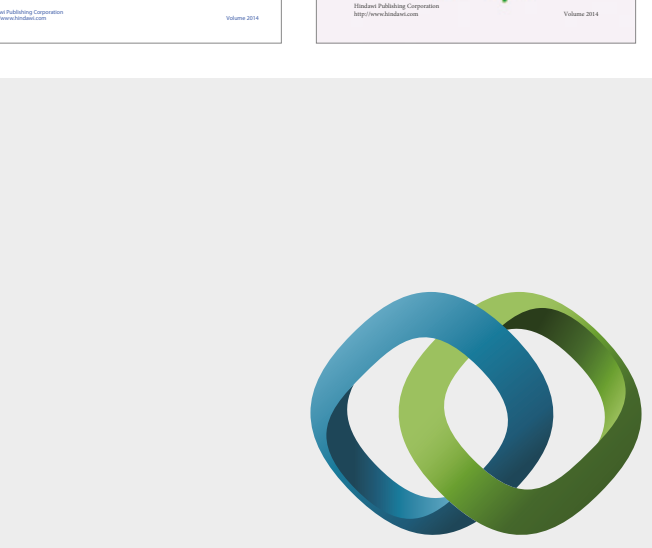

\section{Hindawi}

Submit your manuscripts at

https://www.hindawi.com
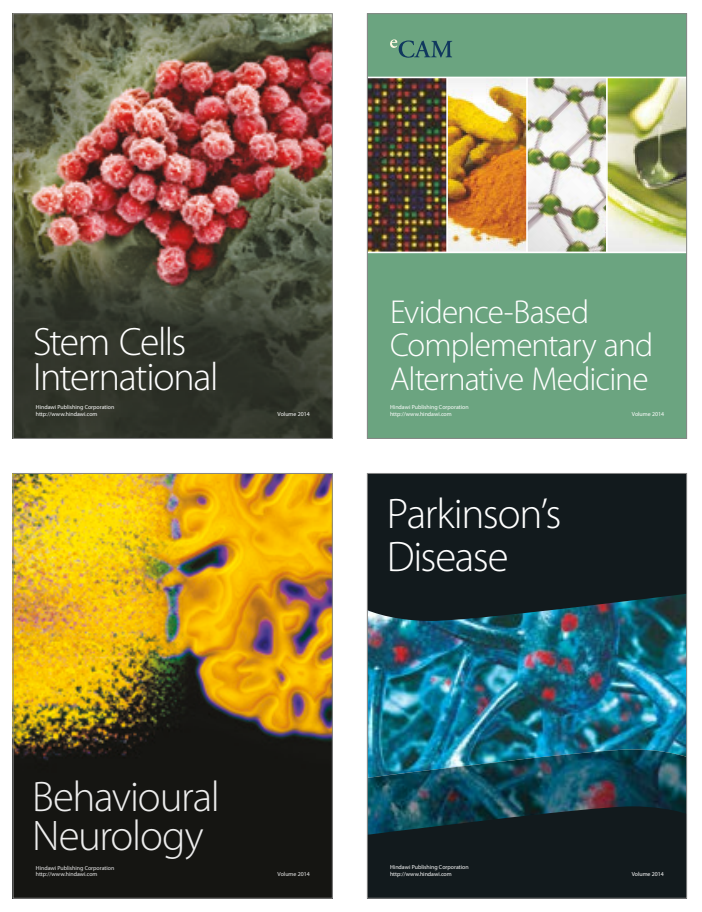
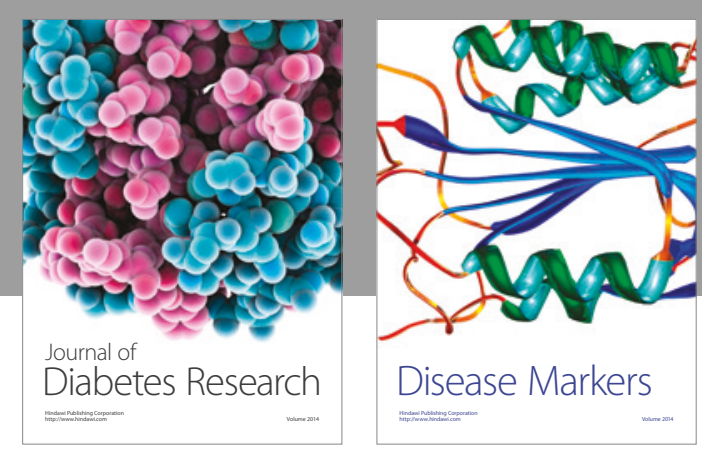

Disease Markers
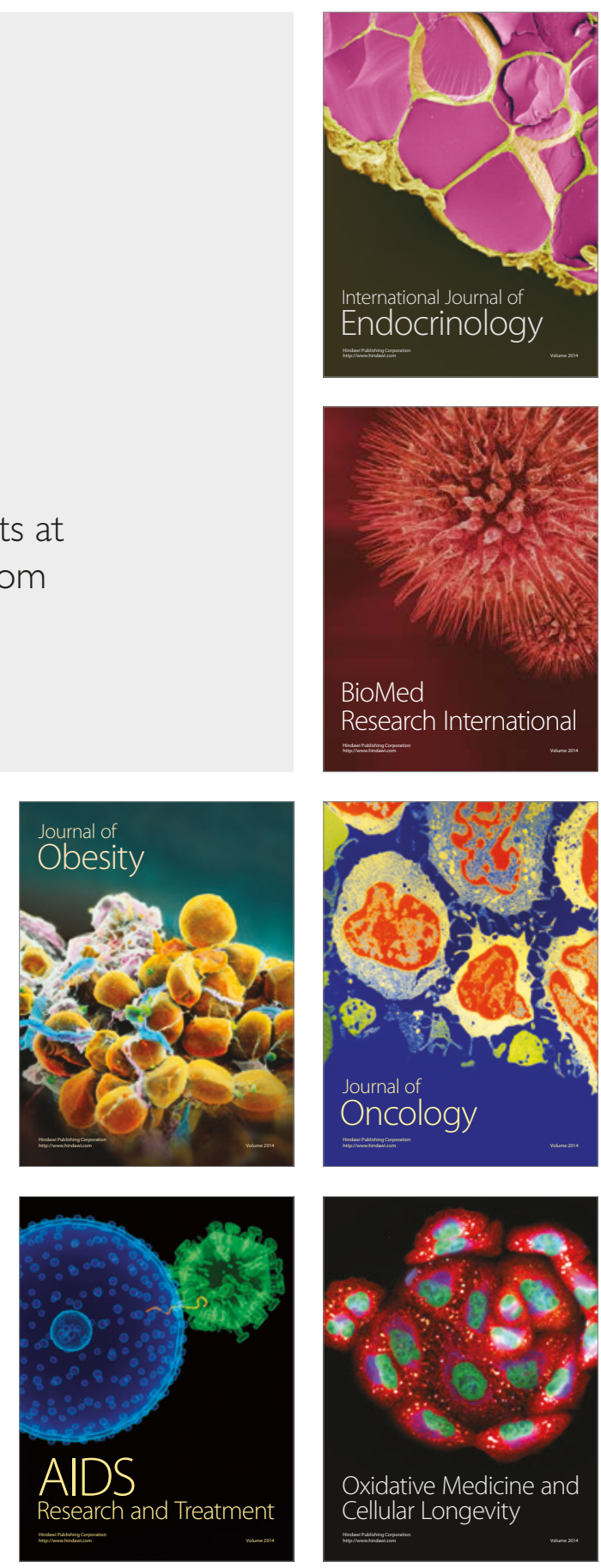